\title{
Islamic principles and decision making in bioethics
}

\section{To the Editor:}

A recent Commentary ${ }^{1}$ makes interesting points about Islamic ethics. In response to the author's explanation of the Iranian experience, we would like to add some comments.

First of all, one of the intriguing aspects about Islam is that it has a dynamic jurisprudence. This quality has paved the way in recent decades for the approval in Iran of some laws in the field of medical ethics that address emerging issues in biomedical sciences and technologies. We refer readers interested in the particulars of these laws ("Deceased and Brain Dead Patients Organ Transplantation (2000)" Donation to Infertile Spouses (2003)"3, and "Therapeutic Abortion (2005)"4) to some of our previously published articles ${ }^{5-8}$.

Islamic scholars have proposed some wellknown Islamic principles to consider for ethical decision making, namely the principle of "the Public Interest" (Maslaha), the principle of "Do no Harm" (La Darar wa la Derar), the principle of "Necessity" (Darura) and the principle of "No Hardship" (La Haradj).

According to the principle of Maslaha, an act is advisable and proper if it results in the most benefits or confers welfare for the most people. Furthermore, according to the principle of $L a$ Darar wa la Derar, it is prohibited to cause a loss to another person or to sustain a loss. The principle of Darura permits the use of the forbidden under circumstances of necessity; for instance, although Muslims are not allowed to eat the meat of carrion (carcass of a dead animal), it is permissible to eat it when a person's life is in danger.

In keeping with some verses of Holy Quran, such as the one stating that "...He (God) has not laid upon you any hardship in religion..." (22:78), no intolerable difficulties have been imposed on Muslims in Islam. The rule of $L a$ Haradj stands for this meaning. According to this concept, if fulfilling any obligatory duty leads to extreme difficulty, the person will be exempted from such religious deed. As an illustration, fasting through the month of Ramadan is mandatory in Islam; however, it is stated in the Holy Quran that "...So every one of you who is present (at his home) during that month should spend it in fasting, but if any one is ill, or on a journey, the prescribed period (should be made up) by days later. Allah intends every facility for you; He does not want to put to difficulties...(2:185)."

These Islamic principles, which are considered when issuing decrees and approving laws in regards to 'newly emerged' queries, can be used for decision-making in contemporary clinical bioethics.

Second, in the case of thalassemia, the Iranian experience of preventative screening has been successful and may be used as a model. As the author of the Commentary ${ }^{1}$ has pointed out, the option of therapeutic abortion in cases of thalassemia was not available when the national program of screening began in 1996. Currently, couples have the opportunity to consult with geneticists before marriage. There are also facilities for prenatal diagnosis of genetic disorders. Selective therapeutic abortion would be possible if the diagnosis of beta-thalassemia is affirmed. Consequently, there is not a compelling desire for couples to separate in the cases of minor thalassemia. Moreover, it is envisaged that marriage of individuals with minor thalassemia with unaffected individuals may possibly spread these hemoglobinopathies in the population. Accordingly, it is preferable to strengthen the system for early prenatal diagnosis. In addition, we can suggest advanced assisted reproduction technologies (ARTs) to couples who have a history of familial disorders, including thalassemia.

Considering the need for effectively integrated genetic services, the World Health Organization (WHO) Regional Office of the Eastern Mediterranean has undertaken a number of initiatives in recent years, including the Regional Consultation on Genetic Disease Prevention and Care in Riyadh, Saudi Arabia (2005). Iran and many other countries in the region have undertaken the implementation of a national community genetic service. It is worth noticing that by providing qualified professionals and advanced equipment, more than 120 centres (public and private) for genetic consultation have made these services available to health-care givers in different provinces of Iran.

Finally, the ever-increasing complexity of the intersection of medicine, religion, ethics and law necessitates better understanding and analysis of medical ethics issues and the provision of culturally adapted solutions. The compilation the Specific National Ethical Guidelines for Biomedical Research (2005) has been an important effort in Iran in recent years ${ }^{8}$. It is noteworthy that "Ethical Guidelines for Genetic Research" is one of the topics in which ethics in prenatal diagnosis, confidentiality of genetic data, ethics in gene therapy, and ethics in genetic consultation are addressed along with the general guidelines. The codes are in accordance with the international declarations and have been customized according to Islamic codes and Iranian cultural issues. Indeed, there is no restriction on genetic research in Iran; however, moral principles and ethical codes must be completely followed. Prenatal diagnosis is permissible only if it is concerned with the health of mother or fetus. Eugenic research is prohibited.

\section{Bagher Larijani \& Farzaneh Zahedi Anaraki}

Medical Ethics and History of Medicine Research Centre and Endocrinology and Metabolism Research Center, Medical Sciences/University of Tehran, 5th floor, Shariati Hospital, University of Tehran, North Kargar Avenue, Tehran 14114, Iran. Correspondence should be addressed to F.Z.A. (fzahedi@sina.tums.ac.ir)

1. Al Aqeel, A.I. Nat. Genet. 39, 1293-1298 (2007).

2. The Deceased and Brain Dead Patients Organ Transplantation Act. Ref. No. H/24804-T/9929 (2000).

3. The Iranian Parliament. The Embryo Donation to Infertile Spouses Act. Ref. No. 33704 (2003).

4. The Therapeutic Abortion Act. Ref. No. 2/85876 (2005).

5. Larijani, B., Zahedi, F. \& Taheri, E. Transplant. Proc. 36, 1241-1244 (2004).

6. Akrami, S.M., Osati, Z., Zahedi, F. \& Raza, M. Transplant. Proc. 36, 2883-2887 (2004).

7. Larijani, B. \& Zahedi, F. J. Relig. Health 46, 399-408 (2007).

8. Larijani, B. \& Zahedi, F. Indian J. Med. Ethics III, 130 (2006).

9. Larijani, B. \& Zahedi, F. Dev. World. Bioeth. advance online publication, doi:10.1111/j.14718847.2006.00180.x. (5 January 2007). 